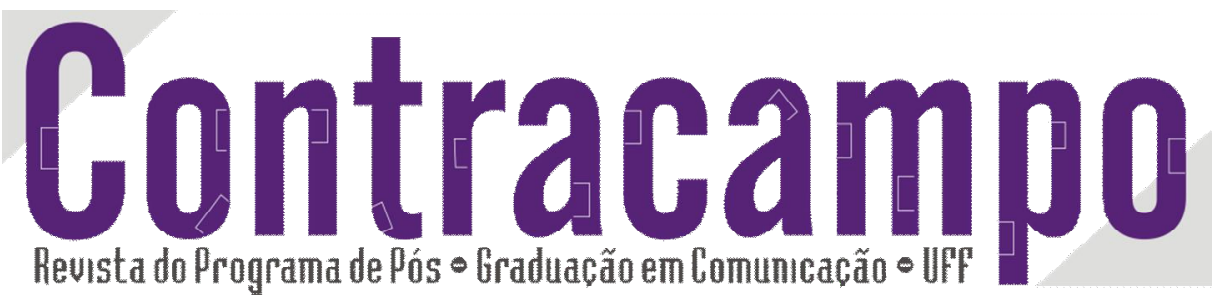

\title{
Um balanço dos estudos de esporte no Congresso Brasileiro de Ciências da Comunicação de 2012
}

\section{A balance of sport studies at the Brazilian Congress of Communication Sciences, 2012}

Rafael Fortes

raffortes@ hotmail.com

Professor da Universidade Federal do Estado do Rio de Janeiro (Unirio), onde coordena o Laboratório de Comunicação e História (LaCHi). Atua também no corpo permanente do Programa de Pós-Graduação Interdisciplinar em Estudos do Lazer da Universidade Federal de Minas Gerais (UFM G).

\section{PPGCOM}

Ao citar este artigo, utilize a seguinte referência bibliográfica

FORTES, Rafael. Um balanço dos estudos de esporte no Congresso Brasileiro de Ciências da Comunicação de 2012. In: Revista Contracampo, v. 30, n. 2, ed. agosto-novembro ano 2014. Niterói: Contracampo, 2014. Págs: 83-98.

Enviado em: 22 de jul. de 2014 Aceito em: 24 de ago. De 2014

\section{Edição 30/2014}

Ensaio temático "Tabloidização na mídia"

Contraca mpo

Niterói (RJ), v. 30, n. 2, ago-nov./2014

e-ISSN 2238-2577

A Revista Contracampo é uma revista eletrônica do Programa de Pós-Graduação em Comunicação da Universidade Federal Fluminense e tem como objetivo contribuir para a reflexão crítica em torno do campo midiático, atuando como espaco de circulação da pesquisa e do pensamento acadêmico. 


\section{Resumo}

0 artigo analisa os trabalhos do Grupo de Pesquisa (GP) Comunicação e Esporte publicados nos anais do XXXV Congresso Brasileiro de Ciências da Comunicação (CBCC), realizado em setembro de 2012, tendo o esporte como tema central. Foram lidos todos os 33 artigos relativos ao GP Comunicação e Esporte. Do ponto de vista qualitativo, discute-se a consistência teórico-metodológica e a observância de parâmetros de cientificidade. Conclui-se que diversos trabalhos ainda apresentam fragilidades nestes aspectos. Do ponto de vista quantitativo, levou-se em conta questões como a modalidade esportiva analisada e 0 tipo de mídia/material investigado. A análise mostra que a ampla maioria é dedicada ao futebol e que a mídia mais frequente como fonte e/ou objeto é a internet.

Palavras-chave: esporte; metodologia; Intercom.

\section{Abstract}

The article analyzes the papers of the Research Group (RG) Communication and Sport published in the proceedings of the XXXV Brazilian Congress of Communication Sciences (CBCC), held in September 2012, having sport as a central theme. All 33 articles on Communication and Sport GP were read. From a qualitative point of view, we discuss the theoretical and methodological consistency and compliance with scientific parameters. It is concluded that several studies still show weaknesses in these respects. From the quantitative point of view, we took into account the sport analyzed and the type of media / materials investigated. The analysis shows that the vast majority of them is dedicated to football and that the most common media as a source and / or subject is the internet.

Keywords: sport; methodology; Intercom. 
“(...) as conquistas institucionais são condições necessárias, mas não garantem o fortalecimento teórico de um campo" (LOPES, 2006, p. 18)

$\mathrm{N}$

os últimos anos, tem crescido a atenção em relação ao esporte na Comunicação. ${ }^{1}$

Entre as evidências disto estão ter sido tema de dossiês de revistas científicas da área, ${ }^{2}$ o lançamento de livros, a aprovação de projetos de pesquisa de mestrado e doutorado (inclusive em programas de pós-graduação onde não há professores cujo objeto principal de investigação é o esporte) e a escolha, pela Sociedade Brasileira de Estudos Interdisciplinares da Comunicação (Intercom), do esporte como tema do congresso nacional e dos congressos regionais realizados em 2012.

O objetivo deste artigo é analisar os trabalhos apresentados no Grupo de Pesquisa (GP) Comunicação e Esporte no XXXV Congresso Brasileiro de Ciências da Comunicação (CBCC), realizado em setembro de 2012 na Universidade de Fortaleza (Unifor). ${ }^{3}$ Promovido anualmente pela Intercom, o $\mathrm{CBCC}$ é o maior congresso brasileiro da área. Nele, os grupos de pesquisa constituem o espaço privilegiado para a apresentação de artigos.

Sobre o recorte adotado, cabe dizer que: a) há seleção de trabalhos $;^{4}$ b) a maioria dos que apresentam são mestrandos ou têm titulação superior (são, portanto pesquisadores formados ou em processo de formação). ${ }^{5}$

Proponho um balanço de produção com recorte específico, dialogando com a tendência apontada por Lopes: "o pensamento epistemológico no campo da Comunicação no Brasil constitui uma perspectiva recente que se manifesta no crescimento de análises auto-reflexivas" (2006, p. 25). ${ }^{6} \mathrm{Se}$, por um lado, considero

1 Versões anteriores deste trabalho foram apresentadas em congressos científicos. Agradeço as críticas e comentários recebidos.

2 Para citar três: Comunicação, Mídia \& Consumo, v. 8, n. 21 (2011), Logos, ed. 33, vol. 17, n. 2 (2010); Organicom - Revista Brasileira de Comunicação Organizacional e Relações Públicas, v. 8, n. 15 (2011); Disponíveis, respectivamente, em: 〈http://revistacmc.espm.br/index.php/revistacmc/issue/view/23〉, <http://www.logos.uerj.br/antigos/logos_33/logos_33.htm>

〈http://www.revistaorganicom.org.br/sistema/index.php/organicom/issue/view/17>. Acesso em 31 jan. 2014.

3 Ficaram fora da amostra os artigos sobre esporte apresentados em outros GPs, bem como os trabalhos do Intercom Júnior (espaço para estudantes de graduação), as conferências e mesas-redondas.

4 De acordo com Bianco (2012), o percentual médio de trabalhos aprovados entre os submetidos fica em torno de $90 \%$. Ou seja, por um lado, há seleção. Por outro, o processo tende a aprovar a ampla maioria dos trabalhos.

5 Considerando mestrado e doutorado como etapas no processo de formação de um pesquisador. 6 Proposta semelhante, no caso da História da Comunicação, é defendida por Ribeiro e Herschmann (2008), em artigo que é, também, um esforço de síntese. 
ainda incipiente o subcampo de estudos de esporte dentro da Comunicação, talvez o aumento da produção apontado no primeiro parágrafo já requeira análises abrangentes, mapeando o que foi realizado e sinalizando tendências. Lopes prossegue afirmando que “(...) torna-se necessário aumentar no campo da Comunicação o movimento de autoreflexividade que se espraia em todo o campo das Ciências Sociais, com particular atenção à reflexão epistemológica crítica e atualizada" (2006, p. 27). Apesar de discordar de parte do diagnóstico da autora no artigo citado, estou de acordo com esta proposta, que foi uma das motivações para a realização deste artigo.

Para tanto, foram lidos todos os 33 artigos publicados nos anais do evento no GP Comunicação e Esporte, totalizando 461 páginas. ${ }^{7}$ Privilegiei uma análise de natureza qualitativa, embora sem ignorar a quantificação, da qual lanço mão em certos momentos. A análise foca quatro aspectos, que correspondem às subdivisões da próxima seção. A primeira discute que modalidades esportivas são privilegiadas e a segunda, os tipos de mídia. O terceiro item se debruça sobre os tipos de estudo e os procedimentos de análise do material empírico. A última seção trata dos parâmetros de cientificidade, mais precisamente o uso de referências bibliográficas e a dinâmica de construção dos textos.

\section{Análise}

\subsection{Modalidades esportivas}

O esporte vem sendo objeto de um Grupo de Pesquisa específico desde, pelo menos, 1999. ${ }^{8}$ Na edição de 2012, a princípio, seria possível supor que o aumento no número total de trabalhos submetidos ao Grupo - um recorde de 33 comunicações poderia favorecer a diversidade quanto às modalidades esportivas. Contudo, isto não ocorreu. Como mostra a tabela abaixo, manteve-se a grande ênfase no futebol, traço histórico da produção do GP.

7 Trabalhei com as indicações de autoria dos trabalhos tal qual publicados nos anais. Elas não necessariamente correspondem a quem efetivamente os apresentou no congresso, por conta da dinâmica própria dos eventos científicos (por exemplo, um artigo pode ter dois ou mais autores, mas ser apresentado por apenas um deles). Além disso, há trabalhos que constam nos anais (e, portanto, foram analisados), mas não foram apresentados. A lista de artigos está disponível em: <http://www.intercom.org.br/papers/nacionais/2012/lista_area_DT6-CE.htm>. Acesso em 05 jun. 2014.

8 Contudo, em alguns anos o GP Comunicação e Esporte perdeu sua autonomia e funcionou fundido com outros dois GPs. 


\begin{tabular}{|c|c|c|c|}
\hline Ano & Total $(\mathrm{T})$ & Trabalhos relativos a futebol $(\mathrm{F})$ & Percentual $(\mathrm{F} / \mathrm{T})$ \\
\hline 2012 & 33 & 23 & $70 \%$ \\
\hline 2011 & 24 & 16 & $67 \%$ \\
\hline 2010 & 19 & 14 & $74 \%$ \\
\hline 2009 & 27 & 15 & $56 \%$ \\
\hline 2008 & 13 & 8 & $62 \%$ \\
\hline 2007 & 16 & 9 & $56 \%$ \\
\hline 2006 & 12 & 6 & $50 \%$ \\
\hline 2005 & 13 & 7 & $54 \%$ \\
\hline 2004 & 14 & 7 & $50 \%$ \\
\hline 2003 & 19 & 10 & $53 \%$ \\
\hline 2002 & 12 & 7 & $58 \%$ \\
\hline 2001 & 10 & 5 & $50 \%$ \\
\hline 2000 & 7 & 5 & $71 \%$ \\
\hline 1999 & 13 & 8 & $62 \%$ \\
\hline
\end{tabular}

Tabela 1: Trabalhos sobre futebol

Fonte: elaboração própria a partir dos trabalhos completos disponíveis no site da Intercom. ${ }^{9}$

Como afirmei em outro trabalho, tal protagonismo do futebol é "compreensível tanto por sua importância na sociedade brasileira quanto pelo peso que tem nos meios de comunicação, sempre ávidos por audiência e público" (Fortes, 2011, p. 602). Entre os dez artigos que não focam o futebol, aparecem modalidades como MMA, vôlei e

9 Disponível em:

<http://www.portalintercom.org.br/index.php?option=com_content \&view=article\&id=1081\&Itemid=134

>. Acesso em 8 nov. 2013. 
rugby. ${ }^{10}$ Ressalto ainda que são raros os trabalhos que têm como foco questões relativas aos esportes, de uma maneira geral. A maioria prefere se ater a uma modalidade específica.

\subsection{Tipo de mídia}

Diferentemente do que se poderia esperar, verificou-se apenas dois trabalhos cujo material empírico é constituído por periódicos impressos. As fontes ${ }^{11}$ investigadas foram: internet (8), televisão (7), rádio (3), questionários/depoimentos/entrevistas (3), impressos (2), livro de memórias (1), cinema (1) e legislação (1). Houve ainda sete trabalhos sem objeto empírico (alguns usos do material empírico são problematizados no próximo item). Nos trabalhos com mais de um objeto, considerei o que foi analisado de maneira mais sistematizada pelo autor.

Tendo em vista a relevância da televisão e do rádio para o futebol e o amplo espaço ocupado por ele nas grades de programação, estas mídias foram relativamente pouco estudadas. ${ }^{12}$ Não obstante, entre os trabalhos promissores estão alguns que se dedicam ao audiovisual. Há investigações em curso sobre, por exemplo, a relação entre as mudanças tecnológicas recentes (como no caso de produtos, plataformas e narrativas possibilitados pelos adventos da TV digital e da internet) e as formas de transmitir o esporte pelos meios de comunicação. Outro traço relevante destes artigos é a preocupação em discutir narrativas e linguagens, sobretudo no caso do cinema e da televisão. Tal perspectiva poderia ser incorporada pelos pesquisadores que se debruçam sobre os demais tipos de mídia, o que contribuiria para o aprimoramento das reflexões.

Destaco ainda trabalhos que dialogam com setores como comunicação organizacional, publicidade e marketing. Tais áreas ainda são proporcionalmente pouco

10 Tendo em vista tratar-se de um subcampo em formação, optei por não identificar individualmente os autores e os artigos analisados (exceto em um momento das considerações finais, quando reconheço a contribuição de três professores para o GP), seja quando as menções são descritivas, elogiosas ou críticas. Meu objetivo é evitar ferir suscetibilidades. Para um esforço de síntese que não menciona os nomes dos autores criticados (mas o faz com os que são elogiados), ver Ribeiro e Herschmann (2008).

11 Uso fonte no sentido comum na História, ou seja, como o material empírico analisado pelo pesquisador.

12 Ressalto que pode ou não haver correspondência entre tema do trabalho e modalidade esportiva. 
investigadas na Comunicação no Brasil e, pela relevância que têm no campo esportivo, ${ }^{13}$ são terrenos promissores de investigação. Há pesquisas sobre mensagens nos uniformes de times de futebol, marketing esportivo, campanhas publicitárias e campanhas de divulgação (de clubes, modalidades, marcas etc.).

Por fim, chama a atenção a internet figurar como tipo de mídia mais investigado. Entre os possíveis fatores explicativos estão a facilidade de acesso ao material e o caráter dinâmico do campo acadêmico comunicacional (um de seus aspectos mais positivos e interessantes), com pesquisadores atentos a novidades e mudanças na sociedade.

\subsection{Tipo de estudo e análise do material empírico}

Uma questão crucial em relação à consistência teórico-metodológica de um trabalho científico é à clareza quanto ao foco (por exemplo, se na produção, no produto, ou recepção), ${ }^{14}$ e a que questões é razoável lançar e possível responder a partir da análise de cada tipo de objeto empírico. Embora apenas dois artigos foquem a recepção, 13 outros trazem afirmações sobre o que (supostamente) são as opiniões, posições, impressões e motivações do público dos meios de comunicação e/ou do esporte. Nenhum destes treze textos cita fonte para a afirmação/informação. Ou seja, é relativamente comum que se lance mão do recurso narrativo de atribuir falas e posições ao público do esporte e/ou dos meios de comunicação, mas sem que o autor apresente fontes que sustentem o que é dito (muito menos realizar estudo de recepção).

Problema semelhante pode ser observado nas considerações finais de aproximadamente metade dos textos, cujas conclusões que extrapolam aquilo que os dados apresentados (ou, ao menos, os dados tal como trabalhados no artigo) permitiriam concluir. Isto ocorre, por exemplo, quando são estabelecidos certos nexos (causais, inclusive) que não se justificam. ${ }^{15}$

13 No sentido definido por Melo (2010) a partir de elaboração do sociólogo Pierre Bourdieu. 14 Trata-se de uma tipologia básica, presente em autores como Barthes (2005). Por conseguinte, não esgota as possibilidades de tratamento de material empírico. O que chama a atenção, como se verá, é que vários trabalhos a ignorem.

15 Uma crítica de tais abusos da pesquisa sobre comunicação pode ser encontrada no texto de Merton e Lazarsfeld (2005), publicado em 1948 nos EUA e disponível desde 1969 no mercado editorial brasileiro. Por exemplo: "o fato de se conhecer o número de horas que as pessoas utilizam o rádio nada nos indica sobre os efeitos daquilo que ouvem" (p. 112). 
Quanto à interpretação e crítica das fontes, destaca-se a variedade de materiais analisados - o que, evidentemente, requer um apelo a ferramentas e abordagens metodológicas diversas. Facebook, comunidades virtuais, plataformas e programas de bate-papo online são fontes relativamente recentes que já receberam a atenção daqueles que investigam o esporte.

Em três casos, os pesquisadores usam instrumentos como questionários, entrevistas ou depoimentos para produzir os dados a serem analisados. Isto se mostra relevante, tendo em vista que nos estudos de esporte brasileiros, mesmo na História, a utilização de fontes orais ainda é tímida (Melo e Fortes, 2010, p. 31). Certamente o conceito de memória social e os estudos em torno do tema ${ }^{16}$ podem auxiliar a problematização das (re)construções do passado - mas é raro que sejam utilizados pelos autores do GP que trabalham com depoimentos e entrevistas. Por vezes, nota-se certa confusão entre história e memória - questão apontada e discutida em um único artigo.

Cabe citar outros problemas. Primeiro, o uso, em alguns artigos, de dados não confiáveis (sobretudo extraídas da internet), sem a respectiva problematização ou cruzamento com outras fontes. Segundo, em 23 trabalhos há trechos em que a fala dos autores, na verdade, está reproduzindo pontos de vista das fontes, sem que isto seja apresentado como tal (ou seja, como a fala de uma fonte, distinta da fala do pesquisador) e com a necessária análise e problematização. Isto é particularmente válido nas seções dos textos em que os pesquisadores escrevem sobre o passado, denominadas: "histórico", "cronologia", "contextualização histórica” etc. Aliás, tais caracterizações e usos do passado frequentemente contém problemas ${ }^{17}$ - discussão que requereria um estudo à parte.

\subsection{Parâmetros de cientificidade}

\subsubsection{Uso de referências bibliográficas}

Entre os aspectos positivos, ressalto a existência de trabalhos que, em maior ou menor medida: a) usam bibliografia científica estrangeira (em inglês ou publicadas em

16 Um bom exemplo de aplicação desta discussão ao esporte encontra-se em Schultz (2007).

17 Por exemplo, a reificação de pioneirismos e mitos fundadores estabelecidos pelo senso comum e/ou pelo jornalismo. De acordo com Domingos (2011), "a história das primeiras performances desportivas é quase sempre generosa com os chamados pioneiros, nomeadamente com aqueles que conseguiram que os seus feitos fossem relatados numa notícia de jornal. Os periódicos tomam assim a função de inscrever a marca memorialista (...)" (p. 81). 
Portugal, por exemplo); b) efetivamente demonstram, pela discussão e pelo uso realizados, a utilidade dos conceitos para iluminar a análise do material empírico; c) buscam questões relativas a outras modalidades para tensionar o que se afirma sobre futebol; d) analisam certos elementos da presença do esporte nos meios de comunicação como construções feitas por estes meios (por exemplo, propor que se pense o "ao vivo" como uma construção das emissoras de televisão).

Dito isto, há duas questões a discutir: a) que referências são usadas (obras científicas x obras jornalísticas e memorialísticas); b) como as referências são usadas (ou seja, se há análise e problematização ao se lançar mão do pensamento dos autores, de conceitos etc.).

No primeiro ponto, o aspecto que mais chama atenção é o uso de livros jornalísticos como se fossem científicos. ${ }^{18}$ Manuais e obras de divulgação também são usados desta forma - a mais frequente delas, Jornalismo Esportivo, do jornalista Paulo Vinícius Coelho.

Mesmo havendo bibliografia científica significativa sobre esporte disponível no Brasil, muitos autores persistem no uso de literatura jornalística e memorialística. Com isso, quase sempre acabam reproduzindo o senso comum - às vezes em relação a temas, acontecimentos e processos que já foram aprofundados, problematizados ou refutados pelas ciências humanas. Um caminho viável para dar consistência aos textos, tendo em vista a disponibilidade em português e/ou no mercado editorial brasileiro, seria o uso de bibliografia de História do Esporte, em substituição aos livros de caráter jornalístico voltados para o passado.

De acordo com Calhoun (2012), esta falta de diálogo com o conhecimento científico existente constitui um procedimento comum na área:

É um problema para se perguntar, até que ponto os pesquisadores que trabalham com questões de Comunicação em diferentes níveis de análise ignoram o trabalho dos outros, como se não houvesse nenhuma razão para imaginar que a economia política ou a cultura influenciariam - ou seriam influenciadas - pela comunicação interpessoal e organizacional (p. 293).

18 Tal prática não parece ser uma característica específica dos estudos sobre o esporte, mas algo presente na disciplina como um todo, especialmente nos trabalhos feitos por pesquisadores que são jornalistas de formação e/ou que têm o jornalismo como tema (ver item 2.4.2). 
O autor refere-se ao desejável diálogo entre diferentes subcampos da Comunicação. No caso do universo que analiso, parece ocorrer algo mais grave: sequer a produção dos pares que escrevem sobre o mesmo tema é utilizada. Não chega a dez o número dos que citam trabalhos apresentados em anos anteriores no próprio GP. De forma geral, raros autores do GP citam uns aos outros.

Penso em duas possíveis explicações para este fenômeno: a) não leem os trabalhos uns dos outros (o que implica problemas graves, do ponto de vista científico); b) leem os trabalhos uns dos outros, mas não encontram motivos para citá-los (o que abre margem para outras discussões, que tampouco cabe desenvolver aqui).

No caso particular do futebol, nota-se em alguns artigos a falta de conhecimento de bibliografia (em português e em outros idiomas) que dê conta de outras modalidades e países. Com isso, às vezes se discorre sobre o futebol e o Brasil como se os fenômenos analisados mercantilização, por exemplo - só ocorressem no país ${ }^{19}$ e fossem específicos da modalidade quando, na verdade, são traços do esporte de alto rendimento no mundo. ${ }^{20}$

No limite, o desconhecimento da produção científica existente contraria a própria noção de ciência, que pressupõe o aprimoramento do que já foi feito. Não se produz ciência a partir de voluntarismos, brilhantismos ou supostos ineditismos (ver item 3). Uma das consequências desta postura é a tendência de certos autores de afirmar que seu trabalho trata de tema inédito. Ora, sem um levantamento bibliográfico extenso e sistematizado, como saber? Como sustentar tal afirmação?

Por outro lado, chama a atenção o uso frequente de autores que, salvo melhor juízo, não se debruçaram com vagar sobre o esporte como objeto de pesquisa, mas o abordaram em textos isolados $^{21}$ de sua trajetória. Em boa parte das obras citadas de pensadores como Muniz Sodré, Roberto DaMatta e Stuart Hall, o esporte aparece como mero exemplo em ensaios que tratam de questões amplas. ${ }^{22}$ Já o ensaio de José Miguel Wisnik (2008) sobre “o futebol e o Brasil”,

19 Ver Ribeiro, 2012, p. 34.

20 Chama a atenção a rara utilização de bibliografia em idiomas que não o português. Digo isso não por nutrir fetiche por autores estrangeiros, mas porque, no caso do esporte, para muitas questões e temas não há bibliografia acessível em português (seja porque autores de língua portuguesa ainda não os abordaram, seja porque os textos em outros idiomas não foram traduzidos). Ademais, há a exigência de aprovação em exame de proeficiência em idioma estrangeiro para ingresso nos cursos de mestrado, e de um outro idioma para o doutorado, bem como a ampla disponibilidade de bibliografia em idiomas estrangeiros (por exemplo, através da plataforma Periódicos, da Capes), o que torna pouco compreensível e justificável que se persista em ignorar a produção científica disponível em outros idiomas.

21 Geralmente de caráter ensaístico. Contudo, no material que analisei, é possível encontrar até o uso de "trabalhos de divulgação" (Souza, 2001, p. 50) destes autores para realizar discussão teórica e conceitual.

22 Refiro-me ao uso específico de trechos em que cada um destes pensadores menciona o esporte (e não, evidentemente, a todas as possibilidades de utilização da vasta obra de cada um). Cumpre destacar o fato 
problemático do ponto de vista científico, é usado da mesma forma. ${ }^{23}$ Raros são os momentos em que a visão de cada um destes quatro autores é problematizada ou mesmo debatida. ${ }^{24}$

Soma-se a isso o raro esforço de contextualizar a produção dos autores utilizados como referências bibliográficas. Por exemplo, nenhum dos textos que lança mão do conceito de espetáculo ou de sociedade do espetáculo problematiza que Guy Debord publicou o livro homônimo nos anos 1960. Seu conceito de espetáculo é utilizado como se a obra tivesse sido escrita no século XXI, para tratar do século XXI. Na mesma linha, usa-se A busca da excitação, de Norbert Elias e Eric Dunning, sem problematizar a aplicação, utilidade e pertinência dos conceitos para o caso brasileiro. ${ }^{25}$

\subsubsection{Narrativa e construção do texto (senso comum x ciência)}

Uma confusão entre jornalismo e ciência, abordada no item anterior quanto à seleção e uso das referências bibliográficas, também foi observada na construção de certos textos. Uma possível hipótese explicativa para tal fenômeno é a proximidade de alguns autores com a narrativa jornalística. (Seria preciso um esforço específico de investigação para realizar uma análise comparativa, de maneira a testar esta hipótese, o que escapa aos objetivos deste artigo.)

Entre os traços desta confusão, é possível apontar:

a) Teor de certas afirmações, que reproduzem o senso comum, especialmente crenças que podem ser observadas no jornalismo sobre futebol, como a naturalização de construções discursivas como "futebol-arte" e "futebol romântico"; por outro lado, há trabalhos que têm o mérito de buscar problematizar estas mesmas noções.

relevante de que Sodré e DaMatta apontaram o futebol e o esporte como objeto de reflexão acadêmica já nos anos 1970-1980 (Helal, 2012; Santos e Drumond, 2013). Este reconhecimento foi crucial para o longo trabalho de legitimação do esporte (a princípio, do futebol) como objeto digno de estudo no âmbito das ciências humanas e sociais.

23 Um exemplo das fragilidades da obra: após discorrer ao longo de algumas páginas sobre "as práticas com bola na Mesoamérica pré-hispânica" (p. 74), Wisnik afirma que "o soule [definido como "uma festa popular praticada em regiões da França ao longo dos séculos desde pelo menos meados da Idade Média"] é citação obrigatória quando se estuda a história do futebol" (p. 76). Ocorre que, em momento algum, o autor diz se tratar de um estudo sobre a história do futebol (e numerosas afirmações ao longo do texto, bem como o estilo do mesmo, deixam claro, para qualquer leitor familiarizado com a historiografia do futebol, que não se trata de um estudo sobre a história do futebol). Além disso, entre as duas citações, há espaço para afirmar que "é sempre vão equiparar o futebol moderno com modalidades pré-modernas de jogos com bola" (p. 75).

24 Refiro-me inclusive ao fato de se ignorar debates críticos em torno da obra destes autores, como é o caso do artigo de Souza (2001) a respeito do pensamento dual de DaMatta. Agradeço a Fabio Peres a indicação deste texto.

25 Sem falar nos problemas específicos da teoria elisiana e de suas aplicações nos estudos do esporte no Brasil (Ribeiro, 2012). Para uma crítica de ambos os aspectos, ver Dias (2010). 
b) Uso de termos como "retratar" e "relatar" para se referir ao próprio artigo, revelando ingenuidade, como se o fazer científico consistisse em elaborar um relato transparente da realidade - em outras palavras, contar como as coisas acontece(ra)m. Trata-se de visão presente no discurso hegemônico do jornalismo brasileiro, mas superada há bastante tempo no âmbito das ciências humanas. ${ }^{26}$

c) Ausência de indicação de fontes, seja para explicitar de onde foi extraída a informação, seja para dar sustentação ao que se está afirmando.

d) Uso de expressões como "quem não se lembra", "é um fato notório", "estima-se" para introduzir afirmações que não se escoram em fontes ou bibliografia.

\section{Algumas considerações}

Referindo-se, em entrevista, ao pouco uso de teoria na Comunicação (e falando a partir da realidade dos EUA), Calhoun considera que "a falta de integração e de reflexão crítica são problemas tanto para permitir que a pesquisa empírica tenha profundidade e acúmulo acadêmico significativo, como para permitir aos pesquisadores de dizer por que seus trabalhos realmente importam" (2012, p. 294). Portanto, penso que boa parte das inconsistências teóricometodológicas mencionadas neste artigo, bem como outras que não foi possível citar e explorar, são, em linhas gerais, traços da área, e não problemas específicos dos estudos do esporte.

Além disso, o viés pós-moderno de certos trabalhos analisados parece indicar adesão a modismos científicos. Alguns têm elementos daquilo que Epstein (1997) chama de fetichismo da novidade (p. 12). De novo, não se trata de fenômeno restrito ao Brasil ou aos estudos do esporte, mas de algo comum na Comunicação:

Doutrinas que viram moda e prêts-à-penser com neologismos meteóricos tomam o lugar de esquemas explicativos definitivos e de aulas magistrais, apagando de passagem os achados de uma lenta acumulação, contraditória e pluridisciplinar, de saberes sobre o assunto, reforçando a impressão de frivolidade do objeto. Talvez, mais nesse campo de conhecimento do que em outros, seja forte a ilusão de pensar que se possa fazer tábula rasa dessa sedimentação e que, nessa disciplina, diferentemente de todas as outras, tudo está por ser criado (Mattelart e Mattelart, 2001, p. 11).

26 Isto não significa, de forma alguma, adesão ao relativismo total que advogam certos autores das ciências humanas e sociais. Nesta discussão, coloco-me próximo ao ponto de vista defendido por Sokal (1998) e Sokal e Bricmont (2010). Discuto este tema na próxima seção. 
Ao se levar em conta a forma e o conteúdo, existem artigos que correspondem ao tipo de produção científica criticado por Sokal (1998) e Sokal e Bricmont (2010). ${ }^{27}$

Como dito antes, poucos apresentam perspectivas críticas em relação ao material empírico (e aos pontos de vista nele presentes), à modalidade esportiva abordada e mesmo ao fenômeno esportivo, de uma maneira geral. Há artigos um tanto ufanistas quanto ao esporte, às competições, ao sucesso financeiro e de audiência etc. Outros adotam um tom apocalíptico, exacerbando críticas sobre mudanças percebidas no presente (não raro, contrapondo-as a um passado esportivo supostamente idílico e superior). Em ambos os casos, nem sempre a argumentação é construída com citação de fontes ou bibliografia que escorem as afirmativas e os pontos de vista. ${ }^{28}$ Tal como ocorre com frequência no jornalismo, a autoridade parece se sustentar mais no lugar ocupado por quem fala do que propriamente na força dos argumentos que esgrime ou na capacidade de demonstrar adequadamente (a partir de parâmetros de validação científicos) a pertinência do que é dito. Afinal, "ter boas intenções políticas não garante que uma análise constitua boa ciência, boa sociologia ou boa história." (Sokal, 1998, p. 5)

Talvez isso explique, em parte, a ainda reduzida presença de artigos sobre esporte nos principais periódicos da área, exceto quando se trata de dossiês, nos quais os critérios para avaliação podem ser distintos daqueles observados no fluxo regular. ${ }^{29}$ Não creio que o preconceito histórico com o tema nas ciências humanas e sociais permaneça um fator explicativo relevante.

Dialogando com Bourdieu (1983), Lopes (2006, p. 17) defende a ideia de que não há produção científica desprovida de política. A posição e as práticas dos agentes dentro do campo científico são, portanto, (também) políticas. Alguns trabalhos do GP se enquadram na pesquisa

27 Para um exemplo de trabalho criticado por Sokal e Bricmont (2010) e disponível no Brasil, ver Kristeva (2005). Utilizado por pesquisadores do esporte, o livro de Wisnik (2008) atende tranquilamente aos parâmetros criticados por Sokal e Bricmont (2010).

28 Referindo-se aos artigos que compõem o livro Universo do futebol: esporte e sociedade brasileira, organizado por Roberto DaMatta e lançado em 1982, Helal (2012) afirma: "o tom ensaístico, sem pesquisa empírica - exceto o trabalho de Guedes - se justifica pela quase ausência de estudos no campo à época" (p. 148). Tal conclusão poderia ser aplicada a parte dos trabalhos analisados - embora tenham sido publicados trinta anos depois...

29 De maneira geral, nas revistas a aprovação de um artigo está sujeita à avaliação de dois pareceristas. Nas publicações mais bem avaliadas costuma haver fluxo intenso de artigos, o que significa, ao menos em tese, critérios de corte mais exigentes quanto à qualidade, o que se reflete na quantidade de trabalhos recusados. Nos dossiês, em geral convida-se um organizador que, por sua vez, convida os pesquisadores a apresentarem seus trabalhos, que nem sempre seguem o regime regular de avaliação por parecer duplo cego. Há, contudo, revistas cujo dossiê consiste em uma chamada aberta de trabalhos, que passam pelo processo normal de avaliação (com parecer duplo-cego). Pode-se ainda adotar um modelo híbrido, em que o dossiê é composto tanto por trabalhos aprovados por avaliação duplo-cego quanto por artigos entregues por convidados. 
administrativa tal qual caracterizada e criticada por autores como Mattelart e Mattelart (2001). Ora, como afirma Sokal (1998), "não há nada de errado com a realização de pesquisas orientadas por uma posição política, contanto que esta posição não cegue o pesquisador para fatos inconvenientes" (p. 5). Cabe indagar: que visões de esporte, de Comunicação e do fazer científico estão implícitas ou explícitas nestes trabalhos? $?^{30}$ Em que medida contribuem para o avanço do conhecimento sobre o campo esportivo e a sociedade em que vivemos (ou a sociedade tema da pesquisa)? Tais perguntas apontam para a necessidade de investigações que reflitam sobre o ofício atual da pesquisa. Trata-se, na verdade, de uma dupla reflexão: a) no plano do tema e do debate social: qual o sentido político (em termos de projetos de sociedade e de visões sobre o esporte, por exemplo) dos trabalhos elaborados pelos pesquisadores? b) no plano dos estudos do esporte na Comunicação: que posições o debate epistemológico (ou a ausência dele) revela?

Como afirma Bourdieu, o campo científico se caracteriza por lutas por "autoridade científica" e "competência científica" (1983, p. 122). Evidentemente, este artigo, bem como o lugar que ocupo (ou pretendo ocupar) no campo podem igualmente ser interpretados neste sentido. De acordo com o autor, no limite, toda escolha científica se articula com um objetivo político (obter prestígio, reconhecimento dos pares etc.). Ao escrever, estou ciente desta reflexão:

Na luta em que cada um dos agentes deve engajar-se para impor o valor de seus produtos e de sua própria autoridade de produtor legítimo, está sempre em jogo o poder de impor uma definição de ciência (isto é, a delimitação do campo dos problemas, dos métodos e das teorias que podem ser considerados científicos) que mais esteja de acordo com seus interesses específicos.

Somente o esforço de reflexão epistemológica e o debate franco podem fazer o campo de estudos avançar. Sequer as raras experiências existentes no Brasil, como a discussão dos usos da obra O negro no futebol brasileiro levantada por Soares (2001), são apropriadas pela maioria dos artigos a respeito da modalidade. ${ }^{31}$

30 Há aqui um feixe de variáveis que se articulam, como a dimensão política (direita, esquerda, centro) quanto à sociedade e ao esporte e a dimensão ética do fazer científico e de suas implicações (por exemplo, declarar ou não conflitos de interesse nos textos que se publica). Tais práticas podem gerar efeitos na sociedade - e não apenas no campo científico. Uma denúncia destas relações, no caso da Economia e de professores universitários que atuam nos EUA, é realizada pelo filme Trabalho Interno (dir. Charles Ferguson, EUA, 2010).

31 Para uma síntese desta discussão e um sumário dos "estudos acadêmicos sobre o futebol brasileiro" focado naqueles que dialogam com a Comunicação e abordam a questão da nação, ver Helal (2012, citação à p. 140). Outro esforço de síntese, voltado para o "campo acadêmico dos estudos sociais do esporte" foi realizado por Gastaldo (2010, citação à p. 7). Para dois balanços da produção historiográfica brasileira sobre futebol, ver Ribeiro (2012) e Santos e Drumond (2013). 
Uma das boas notícias que emergem da amostra abordada é que há pesquisas de mestrado e doutorado sendo realizadas fora dos programas onde há professores doutores cujo tema principal de interesse é o esporte. ${ }^{32}$ Isto sugere que, caso ainda existam resistências ao tema nos 45 programas de pós-graduação que compõem a área, em vários deles ela não impede o ingresso de candidatos de mestrado e doutorado aprovados com projetos voltados para o esporte. $^{33}$

Ainda do ponto de vista do panorama observado, como venho argumentando, é preciso considerar as características e limites que marcam a Comunicação (em geral e no Brasil), bem como a já citada incipiência de vários estudos. No caso específico do GP, cabe considerar a expressiva presença de graduados, mestrandos e mestres (que se encontram no início da carreira de pesquisador) entre os que autores. Soma-se a isso a impressão de que, por uma série de motivos, boa parte dos pesquisadores de ponta das ciências humanas no Brasil pouco participam de congressos no país - sobretudo apresentando artigos em sessões regulares de grupos de pesquisa, grupos de trabalho, simpósios temáticos e afins -, preferindo enviar seus trabalhos diretamente para revistas científicas e/ou, quando participam de congressos, fazê-lo no exterior. ${ }^{34}$ Penso que estes fatores, tomados em conjunto, contribuem para justificar a ocorrência de tantos artigos incipientes na amostra.

Tendo em conta o que foi dito, parece útil apontar sugestões. Duas correspondem a procedimentos do fazer científico:

a) Inovar na aplicação de conceitos, não usando a fórceps o esporte para exemplificar o que dizem autores que tratam de temas diversos, mas buscando, a partir da observação do material empírico, autores e conceitos que efetivamente possam iluminar a interpretação.

b) Isto requer cuidado e sistematização na construção, descrição e análise do material empírico, bem como relatar e justificar as escolhas realizadas.

As demais compõem um programa de pesquisa para o futuro próximo.

a) Lançar mão de abordagens temáticas inovadoras para pensar a relação entre comunicação e esporte (o que vem sendo feito, por exemplo, por alguns pesquisadores do

32 Soma-se a isso a evidente importância, para a constituição, manutenção e crescimento do GP, dos três pesquisadores que atuam em programas de pós-graduação em Comunicação e que historicamente assumem o esporte como tema principal de investigação e orientação: José Carlos (Zeca) Marques (UNESP), Márcio Guerra (UFJF) e Ronaldo Helal (UERJ). Aproximadamente metade dos trabalhos analisados é assinado por orientandos ou ex-orientandos destes professores, além dos artigos deles próprios.

33 Total de programas segundo o site da Capes em 15/1/2014.

34 Agradeço a Cleber Dias por esta observação. Apenas um levantamento mais abrangente poderia indicar se esta tendência se aplica (ou não) ao caso específico do estudos do esporte na Comunicação, o que extrapola os limites deste artigo. 
esporte na televisão, que refletem sobre questões como ao vivo, replay e melhores melhores momentos como construções midiáticas).

b) Analisar criticamente a ampla bibliografia jornalística sobre esporte.

c) Abordar a publicidade e os aspectos econômicos do esporte.

d) Produzir, usar e disponibilizar fontes em diálogo com a história oral (e seus métodos).

Por fim, talvez valha a pena retornar à discussão sobre a trajetória da própria Comunicação. De acordo com Lopes, há na atualidade uma luta para superar hierarquias e configurar "um campo de discurso e práticas sociais cuja legitimidade acadêmica e social vai cada vez mais depender de profundidade, extensão, pertinência e solidez das explicações que produza, do que do prestígio institucional acumulado" (Lopes, 2006, p. 22). Ainda de acordo com a mesma autora, "não resta dúvida de que se trata de um campo [Comunicação] em processo de expansão, tanto quantitativa como qualitativa" (p. 29).

Este artigo representou uma segunda aproximação para observar o estado da arte destas questões no que diz respeito aos estudos que tematizam o esporte (Fortes, 2011). Que venham novos balanços e investigações.

\section{Bibliografia}

BARTHES, Roland. A mensagem fotográfica. In: LIMA, Luiz Costa (org). Teoria da cultura de massa. $7^{\mathrm{a}}$. ed revista. São Paulo: Paz e Terra, 2005. p. 325-338.

BIANCO, Nélia Del. Conferência apresentada na I Sessão Plenária "Ciências da Comunicação em Contexto Lusófono". In: Congresso Brasileiro da Lusocom (Federação Lusófona de Ciências da Comunicação), X., 2012, Lisboa. Realizada em 27 set. 2012.

BOURDIEU, Pierre. O campo científico. In: ORTIZ, Renato (org.). Pierre Bourdieu Sociologia. São Paulo: Ática, 1983. p. 122-155. Disponível em: <http://www.bresserpereira.org.br/Terceiros/Cursos/2010/2010_O_campo_cientifico.pd f>. Acesso em 4 out. 2013.

CALHOUN, Craig. Comunicação como Ciência Social (e mais). Revista Brasileira de Ciências da Comunicação, São Paulo, v. 35, n. 1, p. 275-310, jan.-jul. 2012.

DIAS, Cleber. A sociologia figuracional e os estudos do esporte. Revista Brasileira de Ciências do Esporte, Campinas, v. 31, n. 2, p. 155-169, jan. 2010.

DOMIngos, Nuno. O desporto e o Império Português. In: NEVES, José, DOMINGOS, Nuno (coord.). Uma história do desporto em Portugal. Volume 2. Vila do Conde: QuidNovi, 2011. p. 51-107. 
EPSTEIN, Barbara. Postmodernism and the left. New Politics, vol. 6, n. 2 (new series), p. 1-17, Winter 1997.

FORTES, Rafael. Estudos de esporte na área de comunicação: um panorama e algumas propostas. Revista FAMECOS, Porto Alegre, v. 18, n. 2, p. 598-614, mai-ago 2011. Disponível em: 〈http://revistaseletronicas.pucrs.br/ojs/index.php/revistafamecos/ article/viewFile/9476/6570c $>$. Acesso em 11 set. 2013.

GASTALDO, Édison. Estudos sociais do esporte: vicissitudes e possibilidades de um campo em formação. Logos, v. 17, n. 2, , p. 6-15, 2o. semestre 2010.

HELAL, Ronaldo. Futebol, Comunicação e Nação: a trajetória do campo acadêmico. In: MARQUES, José Carlos; MORAIS, Osvando J. de (org.). Esporte na Idade Mídia: diversão, informação e educação. São Paulo: INTERCOM, 2012. p. 139-168.

KRISTEVA, Julia. A Semiologia: ciência crítica e/ou crítica da ciência. In: LIMA, Luiz Costa (org). Teoria da cultura de massa. $7^{\mathrm{a}}$. ed revista. São Paulo: Paz e Terra, 2005. p. 307-320.

LOPES, Maria Immacolata V. de. O campo da Comunicação: sua constituição desafios e dilemas. Revista FAMECOS, Porto Alegre, v. 1, n. 30, p. 16-30, ago. 2006. Disponível em: <http://www.revistas.univerciencia.org/index.php/famecos/article/view/ 487/411>. Acesso em 4 out. 2012.

MATTELART, Armand; MATTELART, Michèle. História das teorias da comunicação. 4ª . ed. São Paulo: Loyola, 2001 [1995].

MELO, Victor Andrade de. Esporte e lazer: conceitos. Rio de Janeiro: Apicuri, 2010.

MELO, Victor Andrade de; FORTES, Rafael. História do esporte: panorama e perspectivas. Fronteiras, Dourados, v. 12, n. 22, p. 11-35, jul-dez 2010. Disponível em: <http://www.periodicos.ufgd.edu.br/index.php/FRONTEIRAS/article/view/1180/724>.

Acesso em 12 set. 2013.

MERTON, Robert K.; LAZARSFELD, Paul F. Comunicação de massa, gosto popular e a organização da ação social. In: LIMA, Luiz Costa (org). Teoria da cultura de massa. $7^{\mathrm{a}}$. ed revista. São Paulo: Paz e Terra, 2005. p. 103-131.

RIBEIRO, Ana Paula Goulart; HERSCHMANN, Micael. História da Comunicação no Brasil: um campo em construção. RIBEIRO, Ana Paula Goulart; HERSCHMANN, Micael (org.). Comunicação e História: interfaces e novas abordagens. Rio de Janeiro: Mauad X/Globo Universidade, 2008. p. 13-26.

RIBEIRO, Luiz Carlos. Futebol: por uma história política da paixão nacional. História: Questões \& Debates, Curitiba, n. 57, p. 15-43, jul.-dez. 2012.

SCHULTZ, Jaime. 'Stuff from Which Legends are Made': Jack Trice Stadium and 
the Politics of Memory. The International Lournal of the History of Sport, vol. 24, n. 6, p. 715-248, Jun. 2007.

SANTOS, João Manuel Casquinha Malaia; DRUMOND, Maurício. A construção de histórias do futebol no Brasil (1922 a 2000): reflexões. Revista Tempo, Niterói, v. 17, n. 34, p. 19-31, jan.-jun. 2013.

SOARES, Antonio Jorge. História e a invenção de tradições no futebol brasileiro. In: HELAL, Ronaldo; SOARES, Antonio Jorge; LOVISOLO, Hugo. A invenção do país do futebol: mídia, raça e idolatria. Rio de Janeiro: Mauad, 2001. p. 13-50.

SOKAL, Alain D. What the Social Text affair does and does not prove. Critical Quarterly, v. 40, n. 2, p. 3-18, Jul. 1998.

SOKAL, Alan; BRICMONT, Jean. Imposturas intelectuais: o abuso da ciência pelos filósofos pós-modernos. $4^{\mathrm{a}}$. ed. Rio de Janeiro: Record, 2010.

SOUZA, Jessé. A sociologia dual de Roberto da Matta: Descobrindo nossos mistérios ou sistematizando nossos auto-enganos? Revista Brasileira de Ciências Sociais, [S.1.], vol. 16, n. 45, p. 47-67, fev. 2001.

WISNIK, José Miguel. Veneno remédio: o futebol e o Brasil. São Paulo: Companhia das Letras, 2008. 